\title{
Critical assessment of small bowel biopsy in children
}

\author{
J. F. T. GLASGOW, C. W. B. CORKEY, AND A. MOLLA \\ The Department of Child Health, The Queen's University of Belfast
}

SUMMARY 176 biopsies of small bowel mucosa taken during a 5-year period from 162 children were reviewed, and 92 of them were subjected to quantitative measurement using surface/volume ratio and intraepithelial lymphocyte counting. There was good general agreement between stereomicroscopical appearance of fresh tissue, routine pathology reporting, and our independent histological assessment. Most of those in which there was divergence of opinion (11-15\%) had intermediate mucosal changes. There was a significant difference between the surface/volume ratio for each of the three grades of histology $(P<0.001,<0.001,<0.01)$, indicating a relationship between qualitative and quantitative methods of assessment. The range of measurements in intermediate biopsies overlapped those of the other two grades. In the 92 biopsies there was a correlation between surface/ volume ratio and intraepithelial lymphocyte count $(\mathrm{r}=-0.56 ; \mathrm{P}<0.001)$ which may reflect our clinical experience, in that $88 \%$ of the biopsies were graded as either normal or flat (probable coeliac disease). Very short children had shorter villi than those with nonspecific diarrhoea and a more normal height.

Small bowel biopsy is the key investigation for the diagnosis of enteropathies, such as coeliac disease, and it is imperative that a proper interpretation of the intestinal histology is made. This is usually assessed subjectively and may be made more difficult by poor orientation of the mucosa before histological sectioning. In reviewing our experience we collated the histological material from all children biopsied between January 1972 and December 1977 inclusive. More than half of the specimens had also been subjected to morphological assessment using the techniques of surface/volume ratio measurement (Dunnill and Whitehead, 1972) and intraepithelial lymphocyte counting (Ferguson and Murray, 1971).

\section{Methods}

Patients. 162 patients (aged 3 months to $14 \cdot 5$ years) had biopsies of the small bowel mucosa because of clinical or laboratory features suggesting small gut enteropathy. A diagnosis of coeliac disease was made in 49 children. 11 others had possible postinfectious diarrhoea, 4 dermatitis herpetiformis, 4 giardiasis, 3 cystic fibrosis without associated bowel pathology, 2 an immunological disorder, 2 short bowel syn-

The Department of Child Health, The Queen's University of Belfast

J. F. T. GLASGOW, senior lecturer

C. W. B. CORKEY, senior registrar

A. MOLLA, registrar drome, and one each with isolated growth hormone deficiency, severe iron deficiency anaemia, and diabetes mellitus with pronounced hepatomegaly (Mauriac's syndrome). The biopsy was normal in 84 children.

Qualitative assessment. Peroral jejunal biopsies were taken under fluoroscopic control, at the ligament of Treitz with a Crosby-Kugler, one-hole, paediatric capsule. The specimen was placed on black filter paper, covered with normal saline, its mucosal surface immediately examined with a Wild stereomicroscope, the majority by one observer (J.F.T.G.), and graded as normal, intermediate, or flat according to the classification of Shmerling (1970). The tissue was then fixed in $10 \%$ formalin and processed for routine histological reporting by a pathologist. The same slides were graded independently (J.F.T.G.) as normal, intermediate, or flat before the pathology report was known. It is these two forms of histology which are referred to subsequently, but it is with the independent grading that quantitative measurements are compared.

Quantitative measurements. These were made without reference to the above findings in 92 biopsies.

\section{Surface/volume ratio (SVR)}

This was measured (Dunhill and Whitehead, 1972)

by viewing the histological specimen through a 
graticule inserted in the microscope eyepiece. Inscribed on the graticule were (15 lines of equal length connecting the vertices of a regular hexagonal point network (Weibel, 1963). SVR is given by the formula $\mathrm{c}: \mathrm{lh}$, where $\mathrm{c}$ is the total number of times a line cuts the epithelial surface, $\mathrm{h}$ the total number of times the end points of a line hit the mucosa between muscularis mucosae and epithelium. At least $\mathbf{2 0 0}$ hits were made. The mucosal volume (MV) is the mean number of hits $h$, for each position of the graticule in relation to the mucosa. The length of the line, 1, projected on the histology was $1.4 \mathrm{~mm}$. Magnification was kept constant throughout.

\section{Counts of intraepithelial lymphocyte (IEL)}

These were made according to Ferguson and Murray (1971). Differential counts of cell nuclei were carried out within the epithelium where the plane of section passed vertically through basement membrane and enterocytes. Their nuclei and those of lymphocytes could thus readily be distinguished; goblet cells were ignored. In histologically normal and intermediate specimens, counts were made on the sides and tips of the villi and in flat biopsies surface cells were counted. In most biopsies at least 400 epithelial cells were counted. In a few flat biopsies however, which were small in size with distortion of the epithelial cells, only 200 could be accurately counted. The results were expressed as IEL per 100 epithelial cells.

Normal ranges were derived by plotting cumulative percentages on probability graph paper (Hoffmann, 1963). Statistical comparisons were made using the SPSS system (Nie et al., 1975) and Student's $t$ test.

\section{Results}

Qualitative assessment. By comparison with our independent grading, stereomicroscopical examination graded the majority of normal and flat biopsies correctly (Table 1). This was not so for intermediate changes, as there was a tendency for stereomicroscopy to suggest a degree of abnormality less severe than could be confirmed histologically by us.

Table 1 Independent histological grade compared with stereomicroscopic grade

\begin{tabular}{llrlll}
\hline $\begin{array}{l}\text { Independent } \\
\text { grade }\end{array}$ & \multicolumn{5}{l}{ Stereomicroscopic grade } \\
\cline { 2 - 6 } & Normal & Intermediate & Flat & NE & Total \\
\hline Normal & 95 & 8 & - & 5 & 108 \\
Intermediate & 8 & 11 & 2 & -2 & 21 \\
Flat & - & 8 & 37 & 2 & 47 \\
\hline
\end{tabular}

$\mathrm{NE}=$ Not examined.
Table 2 Independent histological grade compared with pathology report

\begin{tabular}{lllll}
\hline $\begin{array}{l}\text { Independent } \\
\text { grade }\end{array}$ & \multicolumn{4}{l}{ Pathology report } \\
\cline { 2 - 5 } & Normal & Intermediate & Flat & Total \\
\hline Normal & 93 & $12^{*}$ & - & 105 \\
Intermediate & - & 19 & - & 19 \\
Flat & - & $4^{*}$ & 44 & 48 \\
\hline
\end{tabular}

*See Table 5.

Comparison of the pathology report with our independent grade tended also to be in general agreement (Table 2). Of the 35 biopsies reported as intermediate however, independent grading was in agreement in 19 and, of the remaining 16,12 were normal and 4 flat; these 16 are discussed below.

Quantitative measurements. The SVR between each of our three independent grades showed highly significant differences (Tables 3 and 4). There was no overlap between the range in normal and flat mucosae, but the SVR of the intermediate grade overlapped each of the others to a considerable degree. Significant differences were also present in MV between normal and flat biopsies. There was no difference between the intermediate and either of the other two grades. Each of the ranges for MV greatly overlapped.

The normal range for lymphocytes per 100 epithelial cells (probability graph plot) was 3-37. IEL counts were significantly different when flat biopsies were compared with other grades. The range in all however, overlapped considerably. There was a significant correlation between the IEL count and $\operatorname{SVR}(\mathrm{r}=-0.56 ; \mathrm{P}<0.001)$, although this was not the case within the normal or flat grades $(r=-0.03)$.

Table 2 shows 19 biopsies about which the pathology report and independent grading were in agreement. There was a difference of opinion about the other 16 specimens (already mentioned). These were coded and submitted to 'blind' quantitative analysis. Data for SVR, MV, and IEL were within the ranges quoted in Table 3, but only SVR and MV provided clear separation between normal and flat grades (Table 5).

We studied 13 biopsies in which the muscosa was graded as either normal or intermediate. These were taken from 10 children with coeliac disease who were taking a gluten-free diet or undergoing gluten challenge (Figure). In 11 the SVR and MV divided those with qualitatively normal mucosa from those with intermediate changes; 2 were not assessed for technical reasons. None with a SVR below a value of 40 or MV above 11 had normal morphology. Gluten challenge tended to reduce the SVR and 
Table 3 Independent histological grading in relation to the quantitative data

\begin{tabular}{|c|c|c|c|c|c|c|c|}
\hline \multirow[t]{2}{*}{ Independent grade } & \multirow[t]{2}{*}{$n$} & \multicolumn{2}{|l|}{$S V R$} & \multicolumn{2}{|l|}{$M V$} & \multicolumn{2}{|l|}{$I E L$} \\
\hline & & Range & $M \pm S D$ & Range & $M \pm S D$ & Range & $M \pm S D$ \\
\hline $\begin{array}{l}\text { Normal range } \\
\text { (probability curve) } \\
\text { Normal } \\
\text { Intermediate } \\
\text { Flat }\end{array}$ & $\begin{array}{l}44 \\
12 \\
36\end{array}$ & $\begin{array}{r}26-64 \\
30-68 \\
6-60 \\
5-29\end{array}$ & $\begin{array}{l}45 \pm 10 \\
27 \pm 15 \\
15 \pm 6\end{array}$ & $\begin{array}{l}8 \cdot 6-12 \cdot 7 \\
8 \cdot 3-13 \cdot 2 \\
8 \cdot 4-13 \cdot 3 \\
8 \cdot 8-26 \cdot 4\end{array}$ & $\begin{array}{l}10 \cdot 9 \pm 1 \cdot 2 \\
11 \cdot 1 \pm 1 \cdot 8 \\
12 \cdot 2 \pm 2 \cdot 7\end{array}$ & $\begin{array}{r}3-37 \\
4-58 \\
9-54 \\
28-92\end{array}$ & $\begin{array}{l}23 \pm 12 \\
32 \pm 15 \\
49 \pm 14\end{array}$ \\
\hline
\end{tabular}

Table 4 Statistical comparison ( $P$ values) of data in Table 3

\begin{tabular}{llll}
\hline Grades compared & $S V R$ & $M V$ & $I E L$ \\
\hline Normal with flat & $<0.001$ & $<0.02$ & $<0.001$ \\
Normal with intermediate & $<0.001$ & $>0.05 \mathrm{NS}$ & $>0.05 \mathrm{NS}$ \\
Flat with intermediate & $<0.01$ & $>0.05 \mathrm{NS}$ & $<0.002$ \\
\hline
\end{tabular}

Table 516 biopsies graded intermediate in pathology report

\begin{tabular}{lclll}
\hline $\begin{array}{l}\text { Independent } \\
\text { histological grade }\end{array}$ & $n$ & $\begin{array}{l}S V R \\
(M \pm S D)\end{array}$ & $\begin{array}{l}M V \\
(M \pm S D)\end{array}$ & $\begin{array}{l}I E L \\
(M \pm S D)\end{array}$ \\
\hline Normal & 12 & $\begin{array}{l}38 \pm 5 \\
(31-47)\end{array}$ & $\begin{array}{l}10 \cdot 4 \pm 1 \cdot 0 \\
(9-12)\end{array}$ & $\begin{array}{l}25 \pm 10 \\
(13-58)\end{array}$ \\
Flat & 4 & $\begin{array}{l}12 \pm 1 \\
(11-14)\end{array}$ & $\begin{array}{l}13 \cdot 8 \pm 1 \cdot 6 \\
(13-17)\end{array}$ & $\begin{array}{l}40 \pm 4 \\
(34-44)\end{array}$ \\
$P$ & & $<0.001$ & $<0.001$ & $<0.001$ \\
\hline
\end{tabular}

Range in parentheses.

increase the MV, while a gluten-free diet reversed these trends. One child who was being gluten challenged had a normal mucosa, but this had been in progress for only one week. One other had intermediate changes although a normal IEL count, which may have been because the biopsy was from the second part of the duodenum. The IEL counts did not always correspond to morphological grading. High counts were noted in 4 children with intermediate changes who were taking a normal diet. Two other patients had normal IEL counts, but in each, challenge with gluten powder, $5 \mathrm{~g}$ daily, had
Table 6 Analysis of quantitative data by presenting complaint in those with normal biopsy

\begin{tabular}{|c|c|c|c|c|}
\hline Presentation & $n$ & $\begin{array}{l}S V R \\
(M \pm S D)\end{array}$ & $\begin{array}{l}M V \\
(M \pm S D)\end{array}$ & $\begin{array}{l}I E L \\
(M \pm S D)\end{array}$ \\
\hline $\begin{array}{l}\text { Diarrhoea } \\
\text { Short stature only } \\
\text { P }\end{array}$ & $\begin{array}{l}12 \\
18\end{array}$ & $\begin{array}{l}49 \pm 9 \\
40 \pm 13 \\
<0.05\end{array}$ & $\begin{array}{l}10 \cdot 3 \pm 1 \cdot 3 \\
11 \cdot 0 \pm 1 \cdot 2 \\
\mathrm{NS}\end{array}$ & $\begin{array}{l}22 \pm 15 \\
20 \pm 9 \\
\text { NS }\end{array}$ \\
\hline
\end{tabular}

begun only one week before; when biopsied again having been on a normal diet for some months each had abnormally high counts (Figure).

Four patients with giardiasis, all of whom had normal mucosae, had widely differing IEL counts; 3 were within the normal range, but one child with hypogammaglobulinaemia and a heavy infestation had a count of 58. Three children with dermatitis herpetiformis and normal mucosae had normal IEL counts $(18,22,25)$ and one, graded as flat, a count of 55 .

Finally, quantitative data in children presenting with short stature (height $<3$ rd centile) in whom no intestinal lesion was found, had a significantly smaller mean SVR than those whose complaint was of nonspecific diarrhoea (Table 6). The MV and IEL counts in the two groups however, were virtually identical.

\section{Discussion}

Jejunal biopsy, now accepted as the key investigation in the diagnosis of small bowel enteropathy, has shown that the range of possible changes in
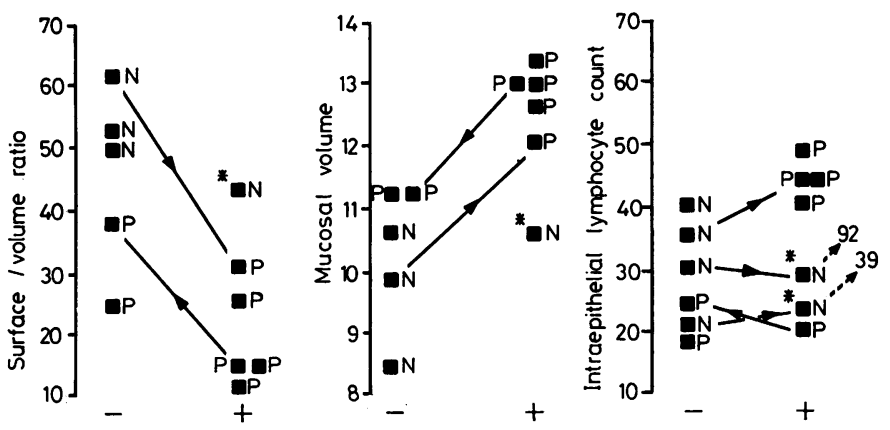

Figure Quantitative measurements in children with coeliac disease in whom biopsies were not flat because the children were on a gluten-free diet $(-)$ or being gluten challenged $(+) ; N$, normal mucosa; $P$, intermediate changes. Arrows indicate serial biopsies in 4 children. Asterisk indicates data on two patients on gluten challenge for one week only. 
various disorders is very wide. As these changes are usually described in purely subjective terms it is not surprising that interobserver variation occurs $(15 \%$ in this study) or that this is more likely in the intermediate part of the range, rather than at either extreme (Table 2). Similar variation was experienced when stereomicroscopical examination of fresh tissue was compared with our independent histological grading (Table 1). Although these two methods of examination are not strictly comparable, differences $(11 \%)$ again tended to be in the intermediate group. Others have reported similar findings (Rubin and Dobbins, 1965; Anderson, 1966). Two further problems which lead to interpretational difficulty are variations in villous architecture found between duodenal and jejunal mucosa (Anderson, 1966), and perhaps more important, technical problems in orientating the specimen before histological sectioning (Brandborg et al., 1959). This is more likely if the biopsy is very small as may be the case if a paediatric instrument is used.

One attempts to combat such inherent variability by taking specimens from a constant site in the gut (Rubin and Dobbins, 1965), striving for perfection in preparing the mucosa so that villi are sectioned vertically, rather than tangentially, and by examining them oneself. It is also helpful to carry out quantitative assessment on biopsies where histological reports are equivocal (Table 5) and, although not the case throughout much of the current study, it should be helpful to have the same pathologist report on all biopsies. Standardisation and comparability are more important with the increasing use of serial biopsies in children with suspected coeliac disease.

Various quantitative assessment methods have been used in the past. Risdon and Keeling (1974) pointed out, that to be of value an assessment must be accurate, reproducible, and have well-defined normal ranges. More arbitrary methods-such as the measurement of villus length and width-fail to satisfy these criteria (Madanagopalan et al., 1965). The methods used here have been validated (Ferguson and Murray, 1971; Risdon and Keeling, 1974) and the normal ranges seem reproducible, although they will not overcome difficulties imposed by specimen distortion or poor histological preparation. Counting of IEL might more accurately be done per unit length of mucosa (Skinner and Whitehead, 1976), but provided the original method is followed, intercentre variation should be negligible.

A highly significant difference in SVR was found between the three histological grades, thus indicating a close relationship between quantitative and qualititative assessments. The fact that the range for normal mucosa overlapped that for intermediate changes accords with the findings of Risdon and
Keeling (1974) and tends to reduce the clinical value of SVR in distinguishing biopsies with mild changes from normal (Table 3). On the other hand, when used to assess serial biopsies from the same individual SVR may be more helpful (Figure).

We confirmed that flat mucosa had a volume significantly greater than normal, which is related to crypt hyperplasia, mucosal swelling, and oedema (Whitehead, 1971). The actual values recorded for MV in each of the three grades were uniformly lower than those of others (Dunnill and Whitehead, 1972; Risdon and Keeling, 1974). Since MV is an absolute measurement ( $(\bar{h})$, as opposed to a ratio, one might expect a greater intercentre variation than with SVR. These differences could be related to such things as different degrees of handling mucosae after biopsy, or to technical factors-for example varying degrees of tissue shrinkage during preparation. Because of these factors and the fact that ranges of the three grades of mucosa overlap, $\mathrm{MV}$ is considered less useful than SVR, particularly in comparing data between different centres, unless identical methods are strictly followed.

Unlike data for SVR and MV in normal biopsies, those for IEL counting showed a distribution which was mildly skewed towards the upper end. This was probably because we had as our group of normal biopsies, tissue which, although architecturally normal, was taken from children, some of whom had bowel symptoms or growth failure, rather than from truly normal individuals, such as the normal siblings of coeliac patients (McNicholl et al., 1976; Mavromichalis et al., 1976). None the less, by using the probability plot as a means of eliminating values at the extremes of the range which are less likely to be completely normal, in spite of their villous architecture, we derived a normal range (and mean) similar to those quoted (Ferguson, 1977).

We have found a significant relationship between morphological alteration in the mucosa and lymphocytic infiltration of the epithelial layer. This in no way implies a causal link between the two and in clinical practice a number of our cases demonstrated that the two modalities of abnormality behaved in an independent manner. A child of 20 months with a fatal defect of cell-mediated immunity, who had intermediate changes, with SVR of $5 \cdot 7$, had an IEL count of only 9 . Several of our flat biopsies characteristic of coeliac disease have also had low IEL counts, which may reflect conscious or unconscious withdrawal of gluten from the diet in children old enough to select their own food. On the other hand, 3 young children had morphologically normal biopsies but abnormally high IEL counts. The most striking was a child with immunodeficiency and heavy giardiasis whose IEL count was 58. The 
other two children with diarrhoea and failure to thrive also had counts $>40$ and were clinically similar to the infants reported by Ferguson et al. (1976). It was thought their high IEL counts may have been an indication of food allergy. Whether this was the case in our patients we cannot be certain, however, it may be significant that in the group of children presenting with nonspecific diarrhoea, the IEL counts were similar to those with short stature per se (Table 6). None the less, a correlation has been shown between SVR and IEL counts and it seems likely that this is because $88 \%$ of our biopsies proved to be either flat, the majority with high counts consistent with coeliac disease, or normal, most having normal IEL counts. Others who have a quite different practice, with many more biopsies of intermediate grade have recently reported no relationship between surface area (c), one of the two variables in the SVR, and the IEL count (de Peyer et al., 1978).

One area where quantitative methods of assessment may prove to be particularly useful is in following serial biopsies from the same patient. So far we have had only a limited experience of this. McNicholl et al. (1976) studied 36 children, using IEL counting, over a number of years and feel that quantitative assessment is better than subjective methods of interpretation.

Very short normal children, the majority with genetic short stature, had villi with significantly smaller surface areas than those presenting with nonspecific diarrhoea (Table 6) and it would seem likely that this is because their villi are actually shorter. This seems a possible explanation since the mucosal volumes, the one other variable, was not significantly different in the two groups. Indeed it seems reasonable that very short children may have proportionately shorter villi.

The time required to carry out these counting techniques is brief. The SVR and MV can with practice be done in 2-3 minutes and the IEL count in a comparable time.

We thank Professor Brian McNicholl and Dr Helen Mawhinney for reviewing this paper.

\section{References}

Anderson, C. M. (1966). Intestinal malabsorption in childhood. Archives of Disease in Childhood, 41, 571-596.

Brandborg, L. L., Rubin, C. E., and Quinton, W. E. (1959).

A multipurpose instrument for suction biopsy of the esophagus, stomach, small bowel, and colon. Gastroenterology, 37, 1-16.

de Peyer, E., France, N. E., Phillips, A. D., and WalkerSmith, J. A. (1978). In Joint Meeting of the European Society for Paediatric Gastroenterology and Nutrition and the North American Society for Paediatric Gastroenterology (abstract). Acta paediatrica Belgica, 31, 173.

Dunnill, M. S., and Whitehead, R. (1972). A method for the quantitation of small intestinal biopsy specimens. Journal of Clinical Pathology, 25, 243-246.

Ferguson, A. (1977). Intraepithelial lymphocytes of the small intestine. Gut, 18, 921-937.

Ferguson, A., and Murray, D. (1971). Quantitation of intraepithelial lymphocytes in human jejunum. Gut, 12, 988-994.

Ferguson, A., McClure, J. P., and Townley, R. R. W. (1976). Intraepithelial lymphocyte counts in small intestinal biopsies from children with diarrhoea. Acta paediatrica Scandinavica, 65, 541-546.

Hoffmann, R. G. (1963). Statistics in the practice of medicine. Journal of the American Medical Association, 185, 864-873.

McNicholl, B., Egan-Mitchell, B., Stevens, F., Keane, R., Baker, S., McCarthy, C. F., and Fottrell, P. F. (1976). Mucosal recovery in treated childhood celiac disease (gluten-sensitive enteropathy). Journal of Pediatrics, 89, 418-424.

Madanagopalan, N., Shiner, M., and Rowe, B. (1965). Measurements of small intestinal mucosa obtained by peroral biopsy. American Journal of Medicine, 38, 42-53.

Mavromichalis, J., Brueton, M. J., McNeish, A. S., and Anderson, C. M. (1976). Evaluation of the intraepithelial lymphocyte count in the jejunum in childhood enteropathies. Gut, 17, 600-603.

Nie, N. H., Hull, C. H., Jenkins, J. G., Steinbrenner, K., and Bent, D. H. (1975). Statistical Package for the Social Sciences, second edition. McGraw-Hill: New York.

Risdon, R. A., and Keeling, J. W. (1974). Quantitation of the histological changes found in small intestinal biopsy specimens from children with coeliac disease. Gut, 15, 9-18.

Rubin, C. E., and Dobbins, W. O. (1965). Peroral biopsy of the small intestine: a review of its diagnostic usefulness. Gastroenterology, 49, 676-697.

Shmerling, D. H. (1970). Peroral intestinal mucosal biopsies in infants and children. Helvetica paediatrica acta, Supplement 22, 5-42.

Skinner, J. M., and Whitehead, R. (1976). Morphological methods in the study of the gut immune system in man. Journal of Clinical Pathology, 29, 564-567.

Weibel, E. R. (1963). Principles and methods for the morphometric study of the lung and other organs. Laboratory Investigation, 12, 131-155.

Whitehead, R. (1971). The interpretation and significance of morphological abnormalities in jejunal biopsies. Journal of Clinical Pathology, 24, Supplement 5, 108-124.

Correspondence to Dr J. F. T. Glasgow, Department of Child Health, The Queen's University of Belfast, Institute of Clinical Science, Grosvenor Road, Belfast BT12 6BJ, Northern Ireland.

Received 30 November 1978 